\title{
Gender Inequality and Women Discrimination
}

\author{
Andrey Shastri \\ (History department,/Baba SahebBhimraoAmbedkar University Raebareily Road Lucknow, India)
}

\begin{abstract}
Men and Women are two wheel of a cart. Female of our country have faced the discrimination throughout the ages now and still to be continued till today and still exists in various form. Usually, discrimination is influenced by cultural norms and tradition, religion, region etc. Biologically and sociologically both are assigned different role. Physically a female role is to look after house, children, family, and relatives and on the other hand men are made for bread earner, for hardship and for struggle for earning. Well all these thinking made our women weaker and deprived from basic things. Both are equal in human right. Women are discriminated in this male dominating society. As a result most of women are unable to understand their own right and freedom. They are not free in this so called "SOCIETY". Thus discrimination not only hamper women future but also impedes the country growth.
\end{abstract}

Keywords: female, discrimination, equality, inequality, gender.

\section{Introduction}

Gender is a common term generally refers to the socially constructed roles, behavior, activities and attributes that a particular society considers appropriate for men and women. Gender basically refers two sexes'i.e men and women. Well biologically both are having different roles and some major responsibilities which they have to fulfill. Physically a female role is to look after house, children, family, relatives and on the other hand men are made for bread earner, for hardship and for struggle for earning. Well all these thinking made our women weaker and deprived from basic things. Both are equal in human right. Women are discriminated in this male dominating society. The distinct roles and behavior may give rise to gender discrimination. Gender discrimination is the prejudicial treatment of an individual or group due to gender. Gender discrimination is not biologically define to anybody rather than it is society, norms, culture, people,etc. who create the atmosphere of gender discrimination. Generally, gender inequality or discrimination word used for "women", because they considered being mostinferior and weaker section of our society. From our total population fifty percent are female population. Among them two-thirds are illiterate. It's really very unbelievable. India is a male dominant society and gender discrimination is customized habitually.

In our country, a woman holds a unique and important position in society. We worship women in many forms and also are respected in the norms of deities for eg: Sara Swati, Durga, Lakshmi, Kali and Chandi.It means we worship women by different names. From the ancient time it is well known that they are most respectable person in the family. There is well and reputed ancient saying which describe or shows the importance of women, they are as follows:-

"Ya Devi SarvaBhuteshu, MatrirupenSansthite, Namastasya, Namastasya, Namastasya , Namo, Namah".

"MatraDevoBhava, PitraDevoBhava, AcharyaDevoBhava".

Well these ancient words clearly shows that women is the another name of goddess as they deserve respect. Earlier women are having a respectable position in society. They perceive equal right over everything as men are having. They are having equal opportunity in religious sacrifices. Now in today's scenario these words have no meaning. Women are not treated equally as they deserve. They need equal respect too because somewhere women are losing their status. They are considered inferior section of our society. This is the reason that most of the women face discrimination in this society. Our society and law of nature has accorded different status and role to men and women.

Gender includes both men and women. For example, when a child birth takes places in a family, then the process of gender differences arose automatically and the process of gendering starts. When a son was born in a family it was celebrated with lot of fun just like festival, and on the same hand when a birth of a daughter takes place in a family, then on the very first day of her birth she was considered as a burden, which they had to carry till their marriage. Despite of living in $21^{\text {st }}$ century, in India still people are having this kind of thinking in their mind. Sometime the gender discrimination begins itself from the family not from the society. These kinds of several factors are responsible for the gender discrimination and also are responsible to create a great barrier in the development of society and in nation. 


\section{Gender Discrimination}

Gender discrimination is not a very new phenomenon in this modern time in India, but it was also prevailing in the ancient time. Women face every kind of discrimination in this society. They are deprived from the basic facilities like education. Women's lives are shaped totally by our customs that are centuries old. They had many boundation also. Well as described by the Manu in 200 BC, " by a young girl, by a young woman , or even by an aged ones, nothing must be done independently, even in her own house. In childhood a female must be subject to her father, in youth to her husband, when her lord is dead to her sons, women must never be independent". So by these words of Manu we can imagine the condition of women at that time, how critical it was. Even today after so many centuries ago, things are changed, we had developed new technology, we talked about changes, globalization, we had seen many changes but one thing that remains constant and that is the status of women in our Indian society. Still they are considered a girl not a person. They are still not safe in this society and not seen with respect. Denial of equality, rights and opportunity and suppression any type on the basis of gender is also gender discrimination. Today from our total population, half of the world's population is women and in that half, two thirds are illiterates. In India and in many countries we are having patrilineal society or male dominating society which means that still the head of the family is father. It is generally seen in northern countries but in the south there are some families which are having matrilineal system, means the head of the family is mother who decides each and every thing. In other words she is the owner of the family. Gender discrimination is customized habitually. Gender discrimination has adverse impact on development goals as reduces economic growth. Practicing Gender discrimination is not the solution of anything. It creates hindrances in the participation of women in social, political and economic activities. It can affect badly our society. In fact, even today at this stage where we talk about equality, in many developing countries including India lot of gender discrimination and gender inequality is still going on in terms of education, health, employment, social values, customs, on the name of caste, as well as on the norm of sexual harassment. Discrimination has its many faces in different forms. Even today educated people had their wrong thinking about women that women had to do nothing in their life except from cooking, cleanliness, and serving whole family including husband, children etc. If a male person will not have respect towards the women then how we can stop this gender inequality or discrimination.

India has witnessed gender inequality from its early history due to its social, economic and religious practices that resulted a wide gap between the position of men and women in the society. How we can forget that men and women are the two wheels of a cart whose equal participation is needed in nation progress. Without the development of one we cannot imagine the development of other. Men and women are the two halves of humanity who need equal support and cooperation and without the one; another one cannot reach up to the excellence. Women face discrimination right from the childhood. They are discriminated in every field. A primary way that parents discriminates their girl children in everything. Mostly illiterates people practices this evil. Education plays a major role in removing gender discrimination from the society. In India we have many people who are happy on the birth of a son and remain unhappy on the birth of a girl child. They did not believe in educating their daughter. Educating women is the prime factor to combat gender discrimination and for the upliftment of women. Our people of Indian society prefer sons over daughters on everything for example if they doesn't have a son then who will look after their family, who will give them food in old age, who will forward their family hierarchy and so on. Birth of a son in a family celebrated with lots of happiness whereas on the same hand birth of a daughter celebrated with lot of sorrow and considered as a burden of a life. Sons are always demandable for these things then consequently, women accorded lower status in the Indian society and then again the process of gender discrimination takes place. Women in India face discrimination in every dimensions, either it is social, economic or political. They had an inferior status over all. Gender inequality prevails in work, education, allocation of food, health care and fertility choices. Many developing countries including India have displayed Gender inequality in education, employment and health. Even everyday through different medium we heard news about the gender discrimination going on in schools, societies everywhere. High levels of gender discrimination are seen against women in the provision of health care, nutrition, education, in Northern and Western India. From health and nutrition point of view girls are more likely to be malnourished than boys both in northern and southern states. This is one of the eg. Of gender discriminated in health. Discrimination of girls in nutrition, preventive and curative health care seeking have an impact on morbidity and mortality. So, from the above explanation it is clear that women are discriminated on different grounds.

\section{Discrimination Faced By Women Through Ancient Time Till Today:}

Women life is full of complication. They are not free in this so called male dominating society, they are $\mathrm{n}$ so much of boundation. Their life starts with discrimination and end with discrimination. Hence, there are some different faces of discrimination which they have to live with it:

1) Sati Pratha

2) Widow marriage 
3) Early marriage

4) Dowry

5) Domestic violence

6) Female infanticide

7) Female foeticide

8) Denial of education

9) Discrimination in food, clothing, and shelter

10) Less respect in family and society

11) No decision -making power

12) Preference of son

13) Gender biasness

14) Social injustice especially towards women.

Solution How We Can Lower The Gender Discrimination Are As Follow:

1) Remove gender inequality from home and then from society.

2) Providing equal education to girls and boys.

3) Giving women equal opportunity in social, economic and in political arenas.

4) Create more social awareness in society and in nation.

5) Most important thing is to create awareness among the parents so that they can understand the importance of girls.

6) Women should be aware regarding their right.

7) Changes should be made in mindset of people of lower section as well as higher section.

8) Women should have decision -making power in the family.

9) Women empowerment is more necessary today.

10) There should be a strong focus in women's human rights, equality, choice, autonomy and reproductive rights. Gender equality and women's human right must be central be central to all goals.

11) As individuals, women must have access to financial resources, income opportunities and equal participation as informed decisions makers at all levels.

12) Women should be more aware about the government schemes and its benefits so, that they can utilize it properly and timely.

13) Changes are needed in the societal norms and the mind-set of the people about women and understand the emerging roles of girls and women for the development of nation.

\section{Review Of Literature:}

RohiniPande and AnjuMalhotra , 'Son Preference and Daughter Neglect in India', shows that son preference in India is a well-documented and its implication shows that is there is more sex ratio, female feticide and higher child mortality rate for girls.Education plays an important role in this matter. In findings it is found that less educated mother wants more sons while more educated mothers did not have this feeling. Many mothers want a balance of sons and daughter.

KokilaMeena, 'Exclusion, Discrimination and deprivation of Women in India', trys to explains the basic differences between discrimination, exclusion and deprivation of women in India .Further explains that women are considered excluded from the society and the condition of women in this society is very cruel. Further this paper shows that exclusion, and discrimination derives from social institution/ societal relations and deprivation is the outcome of exclusion. Different forms of exclusion are the major causes of deprivation of women in India.

Arpita Banerjee, 'Status of Women and Gender Discrimination In India': A State wise Analysis, reveals from her study that there are some states in India where gender discrimination is higher. Women is lagging behind in terms of education,health, employment, social status and so on. Means they are not treated equally in worldwide. There is strong disparity seen in different states. Whereas in issue like declining sex ratio, the developed states are performing very badly owing to the factors like excessive son preference, patriarchal social structure, patrilineal property transfer, religious and ritualistic practice, lower status ascribed to women, prejudice against girl children through the use of modern techniques of sex selective abortion. So in conclusion it can be said that government of these states should frame policies and enforce it through the proper use of machinery so that these extreme form of gender discrimination can be reduced immediately.

\section{Some Consitutional Provision For Indian Women:}

After Independence several changes are made in our constitution. However many changes are made in favor of women also, so that women and men can enjoy equal status in life. There is no difference in the eyes of 
law. Men and women are equal without any kind of having discrimination. Our law treats men and women equally.

In our Constitution there are some legal provision for women and equal opportunities in political, economic and social sphere.Article14 provides men and women equal right and opportunities in the political, economic and social spheres .Article 15 prohibits any kinds of discrimination on grounds of religion, faces, caste etc. Article 15(3) emphasis that the state shall make special provision for women and children. Article 16 provides equality of opportunity in matter relatingto employment by the state. Article 39(a) emphasis that the citizen men and women equally and had an adequate means of livelihood. Article39(d) says that state should provide equal pay for equal work for both men and women. 73th and $74^{\text {th }}$ Amendment of Indian Constitution reserves one -third (including the number of seats reserved for women of SCs and STs) in Panchayats.A convention on the Elimination of all forms of Discrimination Against Women (CEDAW) was adopted and often described as an International Bill for Right for Women. In 1995, Beijing Conference it is stated that ' women rights are human rights' and it called for integration of women's human right in the work of different human rights bodies of United Nation.In 2001 National Policy for the Empowerment of women was made. The main aim of this policy is to bring about the advancement, development and empowerment of women. It also ensures fundamental freedom to women along with man in all sphere like political, economic, social, cultural and so on. Although our constitution has provided equal rights to men and women over all things. So we are nobody to discriminate women on any ground. In 2005, for the protection of women from these different types of violence, Domestic Violence Act , 2005 passed by parliament. Since violence against women is both a consequence and a cause of gender inequality, primary preventive programs that address gender inequality and tackle the root causes of violence are all essential. UN Secretary General Kofi Annan stated "Gender equality is more than a goal in itself. It is a precondition for meeting the challenge of reducing poverty, promoting sustainable development and building good governance." A true nation cans only success when all kinds of discrimination remove properly from the society. In 1995, Beijing Conference it is stated that 'women rights are human rights' and it called for integration of women's human right in the work of different human rights bodies of United Nation.In 2001 National Policy for the Empowerment of women was made. The main aim of this policy is to bring about the advancement, development and empowerment of women. It also ensures fundamental freedom to women along with man in all spheres like political, economic, social, cultural and so on. So different types of policies and constitutional amendments are made from government side. Now the thing is that we have to make ourselves strong and alert so that we can use it timely for our betterment of future.

\section{Conclusion}

Only making laws and enforcing them is not enough but there is a need of social awakening and change in the attitude of mindset of masses, so that there should be no discrimination on the basis of gender and gave equal right and to women. They are the self-owner of their life. Now the time came when women should empowered themselves. Removal of gender discrimination can help in the women empowerment.Time came where women should fight for her own right. If we really want our half population i.e. women should progress and empowered then it is very necessary to remove different kinds of evils that are still prevailing in Indian society. In this age we should have the motto like--------

"Educate Women, Educate India".

\section{Books:}

[1]. Gupta Natthulal, Women Education Through the Ages, Concept Publishing Company,2000

[2]. Raju M. Laksmipathi, Women Empowerment Challenges and Strategies, Regal Publication, New Delhi.

[3]. Anand,A.S., Justice for Women Concerns and Expressions, Universal Law Publishing Co.

[4]. Das Bhaswati, KhawasVimal, Gender Issues in Development Concerns for the $21^{\text {st }}$ century, Rawat Publication ,2009, New Delhi.

[5]. NawalNitu ,Sharma RK., Domestic Violence against Women Legal Protection, Legistative, and Judicial Aspects , Regal Publication, New Delhi, 2013.

\section{Journal Papers:}

[6]. SivakumarMarimuthu,Gender Discrimination and Women's Development in India, MPRA Paper 10901,2008

[7]. Banerjee Arpita, Status of Women And Gender Discrimination In India: A State wise Analysis,journal of International Journal Of Development Research.Vol.3,Issue,12,December,2013.

[8]. Ahmad Naseen Khan,Women Security and Legal Safeguard in India,Journal of Business Management and Social Sciences Research, Vol 2,No.4,April2013.

[9]. Dharagi J, Malipatil K.S, Basavaraj T.H, Gender Discrimination in India-A Need for Intervention, journal of global economy,vol no. 1 Economy,2007 